\title{
OBESIDADE E COVID-19: UMA REVISÃO INTEGRATIVA
}

\section{REVISÃO INTEGRATIVA}

SEREJO, André Henrique Haddad ${ }^{1}$

SANTOS, Jeferson dos ${ }^{2}$

MELO, Marinete Falcão de ${ }^{3}$

DUTRA, Luz Marina Alfonso ${ }^{4}$

SEREJO, André Henrique Haddad. Et Al. Obesidade e COVID-19: Uma revisão integrativa. Revista Científica Multidisciplinar Núcleo do Conhecimento. Ano 05, Ed. 11, Vol. 01, pp. 05-24. Novembro de 2020. ISSN: 2448-0959, Link de acesso: https://www.nucleodoconhecimento.com.br/saude/obesidade-e-covid-19

\section{RESUMO}

Objetivo: O presente artigo tem como objetivo identificar a relação da obesidade e a COVID-19, caracterizando os principais fatores existentes que convergem para a contaminação desses indivíduos. Pergunta problema: Quais os fatores fisiológicos e epidemiológicos estão atrelados a elevada incidência de COVID-19 em indivíduos

${ }_{1}$ Nutricionista, Especialista em Nutrição Clínica e Funcional, Pós-graduando no Programa de Residência Multiprofissional em Saúde do Adulto e do Idoso, Escola Superior de Ciências da Saúde-ESCS/FEPECS.

${ }^{2}$ Enfermeiro, Pós-graduando no Programa de Residência Multiprofissional em Saúde do Adulto e do Idoso, Escola Superior de Ciências da Saúde-ESCS/FEPECS.

${ }^{3}$ Enfermeira, Pós-graduando no Programa de Residência Multiprofissional em Saúde do Adulto e do Idoso, Escola Superior de Ciências da Saúde-ESCS/FEPECS.

4 Enfermeira, Doutora em Ciências da Saúde pela Universidade de Brasília. Coordenadora do Programa de Residência Multiprofissional em Saúde do Adulto e do Idoso, Escola Superior de Ciências da Saúde-ESCS/FEPECS. 
obesos. Método: Foi realizada uma revisão integrativa da literatura, pesquisa descritiva e com abordagem qualitativa que não teve como propósito exaurir o tema, contudo, procurou elucidar os diferentes achados em relação ao tema no cenário global e para isso foram selecionados 14 artigos, destes, 6 (42,9\%) apresentavam relação com o tema abordado e/ou objetivos do presente estudo e estavam na íntegra. Nenhum foi excluído na etapa de leitura de títulos e resumos, dentre estes, nenhum estava duplicado; 3 (21\%) não apresentavam relação com o tema abordado e/ou objetivos do presente estudo; 1 (7,4\%) era artigo de revisão de literatura sistemática, nenhum trabalhou com amostra pediátrica e teses/dissertações, 5 (35,7\%) não estavam na íntegra. Posteriormente, 6 artigos restantes (42,9\%) apresentavam relação com o tema abordado e/ou objetivos do presente estudo. Resultados: A COVID-19 foi classificada como a maior pandemia do século, acometendo a maioria dos países do mundo, e percebeu-se que os portadores de Doenças Crônicas Não Transmissíveis (DCNT), incluindo a Hipertensão Arterial Sistêmica (HAS), Doenças Cardiovasculares (DCV), Diabetes Mellitus (DM), patologias pulmonares e a obesidade são os que evoluem de forma mais grave a doença e possuem chances acentuadas de contaminação ocasionadas a repercussões imunológicas. Por ser uma doença nova e que está atualmente em propagação, poucos estudos foram publicados até o momento, correlacionando e explicando a relação entre a obesidade e a COVID-19.

Palavras-chave: Covid-19, obesidade, doenças crônicas não-transmissíveis.

\section{INTRODUÇÃO}

O grupo de viroses denominadas de Coronavírus é composto por agentes desencadeadores de epidemias que acometeram a população mundial nas últimas duas décadas. Essa classe de vírus é responsável pelo desenvolvimento da Síndrome Respiratória Aguda (SRA) e da Síndrome Respiratória do Oriente Médio (SROM) por parte dos indivíduos acometidos (SIFUENTES-RODRÍGUEZ; PALACIOS-REYES, 2020). 
Recentemente, um novo integrante dessa família de vírus foi identificado e caracterizado primeiramente pelo acometimento massivo da população chinesa e alastrando-se em seguida para a esfera global (ZHAO et al., 2020). Classificado como COVID-19 esse patógeno apesar de possuir baixo poder de letalidade, possui grande propagação entre os indivíduos infectados, ultrapassando o número de 3.000 .000 de indivíduos contaminados e mais de 200.000 mortes, tornando-se uma virose que além de estar em plena ascensão mundial, requer esforços combinados entre os diversos continentes e por parte da organização mundial de saúde (OMS) para conter o seu avanço (LI et al., 2020; WANG B. et al., 2020 WANG C. et al., 2020).

Os indivíduos podem contrair o vírus por meio do contato humano direto ou pelo contato com objetos contaminados, funcionando como vetores para o crescimento da COVID-19. Depois da propagação observa-se que a COVID-19 possui um período de replicação no organismo do indivíduo para que os primeiros sintomas possam ser notados e esses podem ser classificados de leves a severos (KAMPF et al., 2020). Estão listados a seguir alguns dos sintomas característicos: tosse, congestão das vias aéreas superiores, mialgia, cefaleia, febre, diarreia, coriza e dispneia. Lai e col. (2020), citam que apesar da dispneia não ser o sintoma observado com maior frequência, ocorrendo em aproximadamente $35 \%$ dos casos, ela é o principal sintoma para diferenciar os pacientes que precisam de suporte terapêutico intensivo dos que não precisam.

Classificada como a maior pandemia do século a COVID-19, atualmente, já acometeu grande parte dos países do mundo e notou-se que entre os indivíduos que desenvolvem a forma mais grave da doença e que tem maior proporção de mortalidade nos diversos países estão os portadores de Doenças Crônicas Não Transmissíveis (DCNTs), incluindo a Hipertensão Arterial Sistêmica (HAS), Doenças Cardiovasculares (DCV), Diabetes Mellitus (DM), patologias pulmonares e a obesidade (DRUCKER, 2020; RYAN; CAPLICE, 2020).

Entre elas a obesidade é uma DCNT multifacetada e que envolve uma série de mecanismos comportamentais e fisiológicos, desencadeando tanto modificações na liberação hormonal, como na função endócrina exercida pelo pâncreas aumentando 
a resistência periférica a insulina, como também no relação entre saciedade e fome permeada pelo controle emocional e físico que, por sua vez, é regulada por hormônios secretados pelo sistema gastrointestinal (IZQUIERDO et al., 2019). Somado a essas alterações o excesso de tecido adiposo é responsável por uma inflamação sistêmica de baixo grau e, ainda, acrescenta-se aos fatores inflamatórios o desbalanço imunológico ocasionado pela obesidade. Por outro lado, sabe-se que os indivíduos eutróficos e saudáveis, definidos pelo Índice de Massa Corporal (IMC) entre 18,5 a $24,9 \mathrm{Kg} / \mathrm{m}^{2}$ e sem a presença de comorbidades, conseguem promover um balanço adequado entre fatores inflamatórios e anti-inflamatórios gerados por diversas situações diárias, como doenças e o exercício físico (ALAM; NG; LARBI, 2012)

Apesar de poucos casos terem sido relatados pela população chinesa, em grande parte pela menor prevalência de obesidade em sua população em comparação com os países ocidentais, a obesidade atualmente está sendo considerada como um dos fatores que aumentam significativamente a letalidade nos indivíduos acometidos pela COVID-19 e diversos estudos têm procurado identificar e esclarecer essa relação (RYAN; CAPLICE, 2020). Por esse motivo, o objetivo desse trabalho é identificar por meio de revisão integrativa da literatura a relação entre a obesidade e a COVID-19 caracterizando os principais fatores existentes que convergem para a contaminação desses indivíduos.

\section{MATERIAIS E MÉTODOS}

Trata-se de uma revisão integrativa da literatura, pesquisa descritiva e com abordagem qualitativa. Para a elaboração da presente revisão integrativa percorreuse as seis fases descritas por Souza, Silva e Carvalho (2010), a seguir: 1) identificação do tema e seleção da questão de pesquisa; 2) estabelecimento de critérios para inclusão e exclusão de estudos; 3) identificação dos estudos pré-estabelecidos e selecionados; 4) categorização dos estudos selecionados; 5) análise e interpretação dos resultados; e 6) apresentação da revisão e síntese do conhecimento.

Na primeira fase foi elaborada a questão norteadora: Quais as evidências relatam a associação da obesidade com a Covid-19 entre os indivíduos? 
O próximo passo foi a definição das palavras chaves, para a estratégia de busca a fim de tornar possível o encontro entre a hipótese e as informações armazenadas em bases de dados diversas.

$\mathrm{Na}$ segunda fase foi levantada a amostragem ou busca na literatura utilizando os critérios de inclusão. Esses critérios para a busca dos dados foram estabelecidos conforme as bases de dados listadas a seguir: Literatura Latino-Americana e do Caribe em Ciências da Saúde (LILACS), Medical Literature Analysis and Retrievel Sistem Online (MEDLINE), Scientific Electronic Library Online (Scielo), Pubmed e Wiley Online Library, durante o período de Abril a Julho de 2020;, na língua portuguesa, inglesa e espanhola; realizados em humanos. Entre os critérios de exclusão foram elencadas as publicações duplas; teses e dissertações; estudos pediátricos; estudos in vitro e em animais e artigos que não se enquadram nos objetivos do referido estudo.

Foram utilizadas as palavras-chave/qualificadores: covid-19; obesidade e doenças crônicas não-transmissíveis, de acordo com o buscador "Descritores em Ciências da Saúde" (DeCS). A busca foi feita realizando diversas combinações entre as palavras citadas por meio dos operadores booleanos $A N D$ e OR.

Um fluxograma foi elaborado para apresentar a síntese do processo de seleção dos artigos. Utilizados os termos da pesquisa acima descritos e a partir dos resultados, filtrados pelos critérios de inclusão, foram escolhidos os artigos pelos títulos e resumos. Foram lidos todos os resumos e títulos para uma primeira triagem e posteriormente os artigos foram avaliados de forma completa para verificação de elegibilidade, a fim de determinar o número de artigos para análise. Nos casos em que a leitura do resumo não era suficiente para estabelecer se o artigo deveria ser incluído, eles foram lidos na íntegra para determinar a sua elegibilidade.

Na terceira fase, para proferir uma melhor análise e discussão, os conteúdos extraídos dos estudos foram subdivididos em categorias temáticas. A seleção dos dados relevantes dos artigos selecionados anteriormente, foi executada de forma sistemática utilizando um instrumento elaborado pelos pesquisadores: quadro sinóptico. Este 
instrumento facilitou a sintetização e a comparação entre os dados encontrados, além de possibilitar a interpretação mais objetiva deles. O quadro continha ano, autoria, local do estudo (cidade e país), tipo de estudo, nível de evidência e periódico.

$\mathrm{Na}$ quarta fase, foi realizada a classificação dos artigos selecionados quanto aos níveis de evidência; sendo obedecida uma hierarquia de evidências (1 a 6) conforme o delineamento das pesquisas. Para uma melhor análise crítica dos artigos préselecionados, foram aplicados os critérios da Agency for Healthcare and Research and Quality.

$\mathrm{Na}$ quinta fase, os artigos foram comparados entre si, na procura de critérios de semelhança e diferenças. Os artigos incluídos no estudo foram agrupados com temática semelhante, sendo criadas categorias. A matriz da síntese do conhecimento dos resultados significativos de cada estudo considerados pertinentes foi: título, objetivo, amostra, principais resultados e categoria temática.

Finalmente, na última fase realizou-se a síntese de todo o conhecimento; sendo que os principais resultados dos artigos incluídos foram analisados e discutidos conforme a categorização descrita anteriormente.

\section{RESULTADOS}

Após a pesquisa dos artigos científicos nas bases de dados anteriormente citadas, constatou-se um total de 14 estudos. Destes nenhum foi excluído na etapa de leitura de títulos e resumos, dentre estes, nenhum estavam duplicados; 3 (21\%) não apresentavam relação com o tema abordado e/ou objetivos do presente estudo; 1 $(7,4 \%)$ era artigo de revisão de literatura sistemática, nenhum trabalhou com amostra pediátrica e teses/dissertações, 5 (35,7\%) não estavam na íntegra. Posteriormente, dentre os 6 artigos restantes (42,9\%), todos apresentavam relação com o tema abordado e/ou objetivos do presente estudo, totalizando 6 artigos elegíveis (Figura 1). 
Figura 1 - Fluxograma de seleção dos artigos para revisão integrativa sobre a relação entre Obesidade e Covid-19.

\begin{tabular}{|l|l|l|l|l|}
\hline \multicolumn{5}{|c|}{ Estudos indicados a partir de busca nas bases de dados: } \\
\hline Pubmed: 6 & Scielo: 4 & Lilacs:0 & Medline: 4 & $\begin{array}{l}\text { Wiley online } \\
\text { Library:4 }\end{array}$ \\
\hline
\end{tabular}

\begin{tabular}{|l|l|l|l|l|}
\hline \multicolumn{5}{|c|}{ Artigos excluídos por leitura de títulos e resumos: } \\
\hline $\begin{array}{l}\text { Artigos } \\
\text { duplicados: 0 }\end{array}$ & $\begin{array}{l}\text { Não } \\
\text { corresponderem } \\
\text { ao objetivo: 0 }\end{array}$ & $\begin{array}{l}\text { Artigos de revisão } \\
\text { simples: 0 }\end{array}$ & $\begin{array}{l}\text { Amostra } \\
\text { pediátrica: 0 }\end{array}$ & $\begin{array}{l}\text { Tese/dissertação: } \\
0\end{array}$ \\
\hline
\end{tabular}

Artigos lidos na íntegra:

14

Artigos excluídos: 8

Não corresponderam ao objetivo da revisão: 3

Fonte: Autores da pesquisa, 2020. 
No quadro 1 apresentou-se a distribuição dos artigos selecionados segundo ano, autor, título, tipo de publicação, nível de evidência, objetivo, métodos, resultados. No total de 6 artigos (Quadro 1).

Quadro 1: Caracterização da produção científica sobre obesidade e covid-19, 2020.

\begin{tabular}{|c|c|c|c|c|c|c|}
\hline Autoria, & Título & $\begin{array}{l}\text { Tipo de } \\
\text { publicaç } \\
\text { ão }\end{array}$ & $\begin{array}{l}\text { Nível } \\
\text { de } \\
\text { Evidên } \\
\text { cia }\end{array}$ & Objetivo & Métodos & $\begin{array}{l}\text { Resultados } \\
\text { principais } \\
\text { observados/ } \\
\text { relatados }\end{array}$ \\
\hline $\begin{array}{l}\text { TAMAR } \\
\text { A et al., } \\
2020\end{array}$ & $\begin{array}{l}\text { Obesida } \\
\text { de como } \\
\text { preditor } \\
\text { de mau } \\
\text { prognóst } \\
\text { ico do } \\
\text { COVID- } \\
\text { 19: uma } \\
\text { revisão } \\
\text { sistemát } \\
\text { ica }\end{array}$ & $\begin{array}{l}\text { Revisão } \\
\text { sistemáti } \\
\text { ca }\end{array}$ & 1 & $\begin{array}{l}\text { Estudar } \\
\text { o } \\
\text { impacto } \\
\text { da } \\
\text { obesida } \\
\text { de no } \\
\text { prognóst } \\
\text { ico e na } \\
\text { gravidad } \\
\text { e da } \\
\text { doença } \\
\text { do } \\
\text { COVID- } \\
19 .\end{array}$ & $\begin{array}{l}\text { Uma busca } \\
\text { sistemática e } \\
\text { busca manual } \\
\text { foram } \\
\text { realizadas em } \\
\text { quatro bancos } \\
\text { de dados: } \\
\text { Cochrane, } \\
\text { MEDLINE, } \\
\text { EMBASE } \\
\text { PubMed. Os } \\
\text { artigos de } \\
\text { identificados } \\
\text { foram } \\
\text { selecionados } \\
\text { usando os } \\
\text { critérios de } \\
\text { elegibilidade } \\
\text { escolhidos. Obt } \\
\text { ivemos tres } \\
\text { estudos doorte } \\
\text { co de }\end{array}$ & $\begin{array}{l}\text { Os } \\
\text { resultados } \\
\text { de todos os } \\
\text { estudos } \\
\text { incluídos } \\
\text { foram } \\
\text { consistentes } \\
\text { em afirmar a } \\
\text { contribuição } \\
\text { da } \\
\text { obesidade } \\
\text { como um } \\
\text { fator de } \\
\text { risco para } \\
\text { aumentar a } \\
\text { necessidad } \\
\text { e de } \\
\text { cuidados } \\
\text { médicos } \\
\text { avançados. } \\
\text { Estudo com } \\
\text { a mais alta }\end{array}$ \\
\hline
\end{tabular}




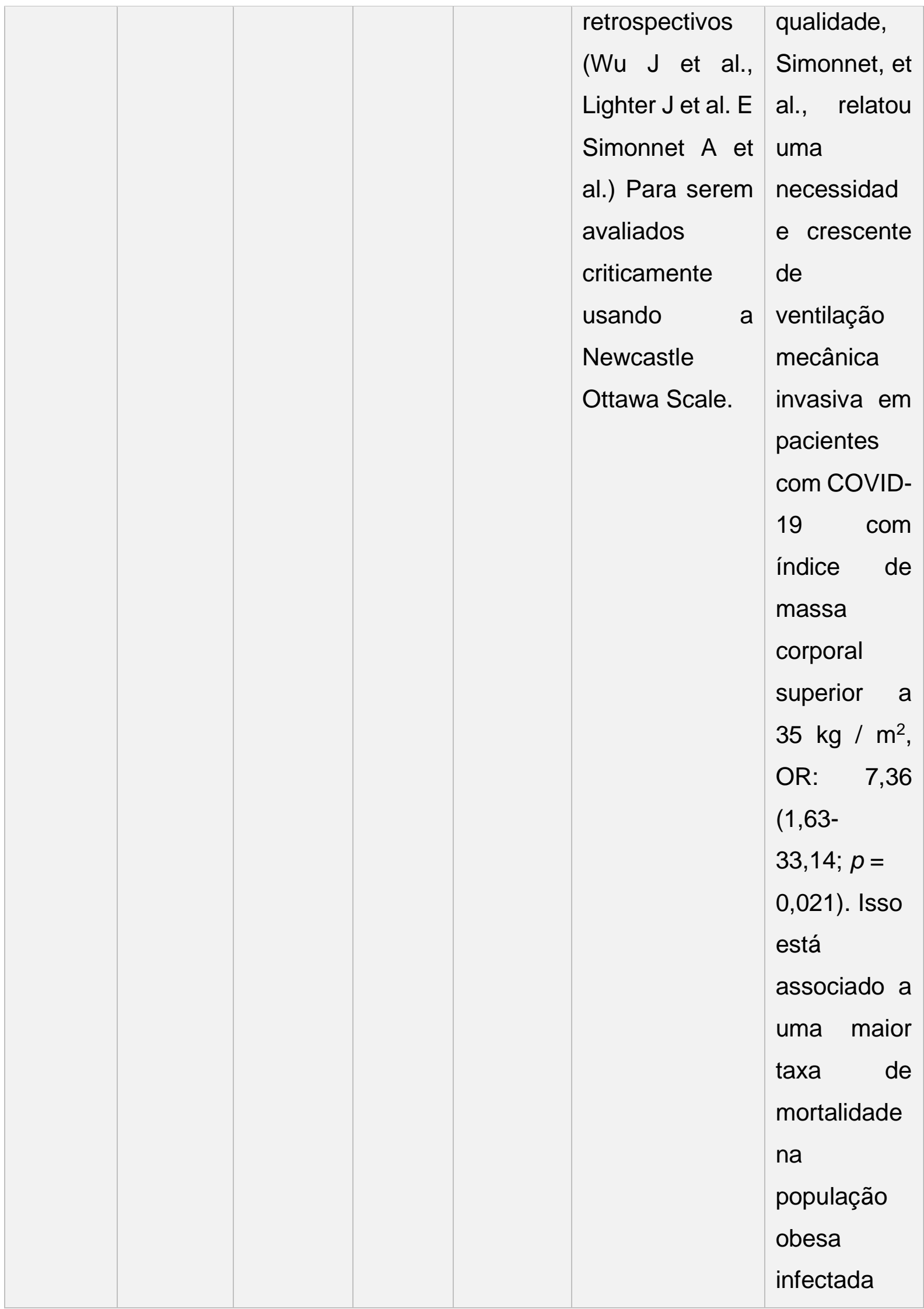




\begin{tabular}{|c|c|c|c|c|c|c|}
\hline & & & & & & $\begin{array}{l}\text { com COVID- } \\
19 .\end{array}$ \\
\hline $\begin{array}{l}\text { ZHENG } \\
\text { et al., } \\
2020\end{array}$ & $\begin{array}{l}\text { Obesida } \\
\text { de é um } \\
\text { grande } \\
\text { fator de } \\
\text { risco } \\
\text { para } \\
\text { para a } \\
\text { severida } \\
\text { de da } \\
\text { coviD- } \\
\text { 19 em } \\
\text { paciente } \\
\text { s com } \\
\text { doença } \\
\text { hepática } \\
\text { gorduro } \\
\text { sa }\end{array}$ & $\begin{array}{l}\text { Ensaio } \\
\text { Clínico }\end{array}$ & 2 & $\begin{array}{l}\text { Investig } \\
\text { ar a } \\
\text { relação } \\
\text { entre a } \\
\text { Doença } \\
\text { Hepátic } \\
\text { a } \\
\text { Gorduro } \\
\text { sa Não } \\
\text { Alcoólic } \\
\text { a } \\
\text { (DHGN } \\
\text { A) } \\
\text { COVID- } \\
\text { 19 em } \\
\text { indivídu } \\
\text { os } \\
\text { obesos }\end{array}$ & $\begin{array}{l}\text { Foram } \\
\text { coletados } \\
\text { dados de } 214 \\
\text { pacientes } \\
\text { obesos } \\
\text { internados com } \\
\text { diagnóstico de } \\
\text { CovID-19 e } \\
\text { DHGNA entre } \\
\text { os meses de } \\
\text { janeiro de } \\
\text { fevereiro } \\
\text { 2020. Foram } \\
\text { coletados } \\
\text { parâmetros } \\
\text { demográficos, } \\
\text { peso, altura, } \\
\text { IMC, doenças } \\
\text { coexistentes e } \\
\text { parâmetros } \\
\text { laboratoriais. }\end{array}$ & $\begin{array}{l}\text { A } \\
\text { associação } \\
\text { da } \\
\text { obesidade } \\
\text { com a } \\
\text { DHGNA } \\
\text { representa } \\
\text { um potencial } \\
\text { contribuinte } \\
\text { para } \\
\text { aumento da } \\
\text { gravidade } \\
\text { em a } \\
\text { pacientes } \\
\text { contaminad } \\
\text { os com a } \\
\text { CovID-19 } \\
\text { (p = 0.029). } \\
\text { Adicionalme } \\
\text { nte, } \\
\text { obesidade é } \\
\text { um fator } \\
\text { significativo } \\
\text { para } \\
\text { incidência } \\
\text { de casos } \\
\text { graves } \\
\text { crícos equivale }\end{array}$ \\
\hline
\end{tabular}




\begin{tabular}{|c|c|c|c|c|c|c|}
\hline & & & & & & $\begin{array}{l}\text { a uma } \\
\text { diferença se } \\
29,9 \% \text { entre } \\
\text { pacientes } \\
\text { obesos e } \\
\text { não obesos } \\
(p=0.021) .\end{array}$ \\
\hline $\begin{array}{l}\text { HUANG } \\
\text { et al., } \\
2020\end{array}$ & $\begin{array}{l}\text { Síndrom } \\
\text { e da } \\
\text { hipovent } \\
\text { ila-ção } \\
\text { no } \\
\text { indivídu } \\
\text { o obeso } \\
\text { e a } \\
\text { gravidad } \\
\text { e da } \\
\text { COVID- } \\
19\end{array}$ & $\begin{array}{l}\text { Relato } \\
\text { de caso }\end{array}$ & 6 & $\begin{array}{l}\text { Analisar } \\
\text { a } \\
\text { evoluçã } \\
\text { o de um } \\
\text { paciente } \\
\text { de } 23 \\
\text { anos de } \\
\text { idade, } \\
\text { portador } \\
\text { de } \\
\text { obesida } \\
\text { de grau } \\
\text { II, } \\
\text { apneia } \\
\text { obstrutiv } \\
\text { a do } \\
\text { sono, } \\
\text { DHGNA } \\
\text { e gota. }\end{array}$ & $\begin{array}{l}\text { Foram } \\
\text { analisados os } \\
\text { dados clínicos } \\
\text { apresentados } \\
\text { pelo indivíduo e } \\
\text { a sua } \\
\text { respectiva } \\
\text { evolução. }\end{array}$ & $\begin{array}{l}\text { A } \\
\text { combinação } \\
\text { entre } \\
\text { obesidade e } \\
\text { a COVID-19 } \\
\text { resulta em } \\
\text { maior tempo } \\
\text { de } \\
\text { ventilação, } \\
\text { menor } \\
\text { velocidade } \\
\text { de } \\
\text { recuperação } \\
\text { do estado } \\
\text { pulmonar. } \\
\text { Ademais, a } \\
\text { associação } \\
\text { com as } \\
\text { outras } \\
\text { comorbidad } \\
\text { es } \\
\text { existentes } \\
\text { aumentam a } \\
\text { ocorrência }\end{array}$ \\
\hline
\end{tabular}




\begin{tabular}{|c|c|c|c|c|c|c|}
\hline & & & & & & $\begin{array}{l}\text { de } \\
\text { desfechos } \\
\text { negativos. }\end{array}$ \\
\hline $\begin{array}{l}\text { GAO et } \\
\text { al., } \\
2020\end{array}$ & $\begin{array}{l}\text { Obesida } \\
\text { de é um } \\
\text { fator de } \\
\text { risco } \\
\text { significat } \\
\text { ivo para } \\
\text { a } \\
\text { severida } \\
\text { de da } \\
\text { COVID- } \\
19\end{array}$ & $\begin{array}{l}\text { Ensaio } \\
\text { Clínico }\end{array}$ & 2 & $\begin{array}{l}\text { Investig } \\
\text { ar a } \\
\text { associaç } \\
\text { ão entre } \\
\text { obesida } \\
\text { de e a } \\
\text { gravidad } \\
\text { e da } \\
\text { COVID- } \\
\text { 19 em } \\
\text { paciente } \\
\text { s com } \\
\text { diagnóst } \\
\text { ico } \\
\text { confirma } \\
\text { do pelo } \\
\text { exame } \\
\text { Reação } \\
\text { em } \\
\text { cadeia } \\
\text { de } \\
\text { Polimer } \\
\text { ase } \\
\text { (PCR). }\end{array}$ & $\begin{array}{l}\text { O estudo foi } \\
\text { composto por } \\
150 \text { pacientes } \\
\text { obesos com } \\
\text { diagnóstico } \\
\text { positivo para } \\
\text { CovID-19. Os } \\
\text { indivíduos } \\
\text { foram divididos } \\
\text { em dois grupos } \\
\text { de acordo com } \\
\text { a gravidade dos } \\
\text { sintomas } \\
\text { apresentados } \\
\text { (leve ou } \\
\text { moderado ou } \\
\text { grave e críticos) } \\
\text { e foram } \\
\text { estratificados } \\
\text { se os pacientes } \\
\text { possuem outras }\end{array}$ & $\begin{array}{l}\text { Pelo método } \\
\text { de análise } \\
\text { de } \\
\text { regressão } \\
\text { logística foi } \\
\text { constatado } \\
\text { que os } \\
\text { pacientes } \\
\text { portadores } \\
\text { de } \\
\text { obesidade } \\
\text { possuem } \\
\text { aproximada } \\
\text { mente três } \\
\text { vezes mais } \\
\text { chance para } \\
\text { o da } \\
\text { desenvolvim } \\
\text { ento da } \\
\text { versão } \\
\text { grave } \\
\text { crítica dacientes } \\
\text { covid-19. } \\
\text { A gravidade } \\
\text { aumentada } \\
\text { nos }\end{array}$ \\
\hline
\end{tabular}




\begin{tabular}{|c|c|c|c|c|c|c|}
\hline & & & & & & $\begin{array}{l}\text { possuem } \\
\text { COVID-19 } \\
\text { está } \\
\text { relacionada } \\
\text { com uma } \\
\text { inflamação } \\
\text { sistêmica } \\
\text { acarretada } \\
\text { pela } \\
\text { obesidade e } \\
\text { também } \\
\text { pela } \\
\text { compressão } \\
\text { mecânica } \\
\text { ocasionada } \\
\text { por ela. }\end{array}$ \\
\hline $\begin{array}{l}\text { SIMON } \\
\text { NET et } \\
\text { al., } \\
2020\end{array}$ & $\begin{array}{l}\text { A alta } \\
\text { prevalên } \\
\text { cia de } \\
\text { indivídu } \\
\text { os } \\
\text { obesos } \\
\text { com } \\
\text { síndrom } \\
\text { e } \\
\text { respirató } \\
\text { ria } \\
\text { aguda } \\
\text { severa } \\
\text { por } \\
\text { coronaví }\end{array}$ & $\begin{array}{l}\text { Estudo } \\
\text { de } \\
\text { coorte } \\
\text { retrospe } \\
\text { ctivo }\end{array}$ & 4 & $\begin{array}{l}\text { Averigu } \\
\text { ar a } \\
\text { relação } \\
\text { entre } \\
\text { IMC e a } \\
\text { necessi } \\
\text { dade de } \\
\text { ventilaç } \\
\text { ão } \\
\text { mecânic } \\
\text { a invadia } \\
\text { em } \\
\text { paciente } \\
\text { s } \\
\text { internad }\end{array}$ & $\begin{array}{l}\text { A amostra foi } \\
\text { separada em } \\
\text { dois grupos, o } \\
\text { primeiro } \\
\text { consistiu em } \\
\text { todos } \\
\text { pacientes que } \\
\text { foram } \\
\text { internados na } \\
\text { UTI de um } \\
\text { hospital francês } \\
\text { entre fevereiro } \\
\text { e abril de } 2020 \\
\text { e que tenham } \\
\text { realizado o }\end{array}$ & $\begin{array}{l}\text { Constatou- } \\
\text { se que dos } \\
124 \\
\text { pacientes } \\
\text { que foram } \\
\text { admitidos na } \\
\text { UTI do } \\
\text { hospital a } \\
\text { maioria } \\
\text { deles era de } \\
\text { sexo } \\
\text { masculino, } \\
\text { aproximada } \\
\text { mente } 90 \\
\text { indivíduos e }\end{array}$ \\
\hline
\end{tabular}




\begin{tabular}{|c|c|c|c|}
\hline $\begin{array}{l}\text { rus-2 } \\
\text { (SARS- } \\
\text { CoV-2) } \\
\text { que } \\
\text { requere } \\
\text { m } \\
\text { ventilaç } \\
\text { ão } \\
\text { mecânic } \\
\text { a } \\
\text { invasiva }\end{array}$ & $\begin{array}{l}\text { os na } \\
\text { unidade } \\
\text { de } \\
\text { terapia } \\
\text { intensiv } \\
\text { a }\end{array}$ & $\begin{array}{l}\text { exame de PCR } \\
\text { para a } \\
\text { comprovar o } \\
\text { diagnóstico. O } \\
\text { segundo grupo } \\
\text { foi constituído } \\
\text { por todos os } \\
\text { pacientes } \\
\text { atendidos no } \\
\text { ano de } 2019 \text { e } \\
\text { que } \\
\text { apresentaram } \\
\text { síndrome da } \\
\text { insuficiência } \\
\text { respiratória } \\
\text { aguda, } \\
\text { indivíduos. Os } \\
\text { dados } \\
\text { demográficos e } \\
\text { clínicos foram } \\
\text { estratificados } \\
\text { (sexo, idade, } \\
\text { peso, altura, } \\
\text { IMC, Diabetes } \\
\text { Mellitus, } \\
\text { Hipertensão } \\
\text { Arterial } \\
\text { foram }\end{array}$ & $\begin{array}{l}\text { a idade } \\
\text { variou entre } \\
51 \text { e } 70 \\
\text { anos. Ao } \\
\text { comparar o } \\
\text { IMC médio } \\
\text { encontrado } \\
\text { entre os dois } \\
\text { grupos foi } \\
\text { observado } \\
\text { que os } \\
\text { indivíduos } \\
\text { com } \\
\text { obesidade } \\
\text { moderada } \\
\text { (IMC entre } \\
30 \text { e } 34,9 \\
\text { Kg/m) } \\
\text { grave (IMC } \\
\text { acima de } 35 \\
\text { Kg/m) } \\
\text { corresponde } \\
\text { u, por sua } \\
\text { vez, } \\
\text { a maioria } \\
\text { da amostra } \\
\text { do grupo } \\
\text { diagnostica } \\
\text { do com }\end{array}$ \\
\hline
\end{tabular}




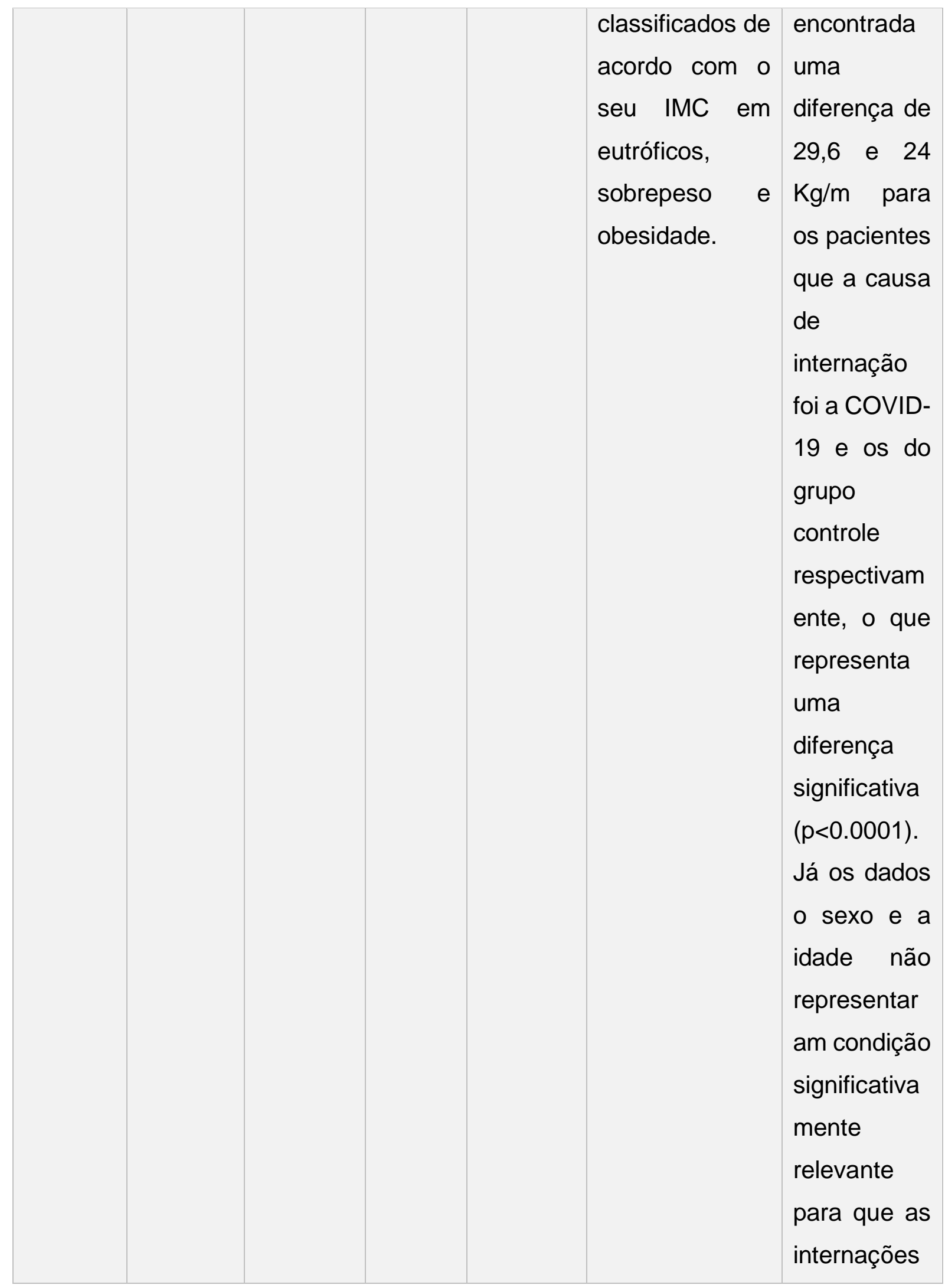




\begin{tabular}{|c|c|c|c|c|c|c|}
\hline & & & & & & $\begin{array}{l}\text { ocorrerem } \\
(p=0.97)\end{array}$ \\
\hline $\begin{array}{l}\text { CAUSS } \\
\text { Y et al., } \\
2020\end{array}$ & $\begin{array}{l}\text { Prevalê } \\
\text { ncia de } \\
\text { indivídu } \\
\text { os } \\
\text { adultos } \\
\text { obesos } \\
\text { entre os } \\
\text { paciente } \\
\text { s com } \\
\text { COVID- } \\
19 \text { na } \\
\text { França }\end{array}$ & $\begin{array}{l}\text { Estudo } \\
\text { transver } \\
\text { sal }\end{array}$ & 6 & $\begin{array}{l}\text { Avaliar a } \\
\text { prevalên } \\
\text { cia de } \\
\text { CovID- } \\
19 \text { em } \\
\text { indivídu } \\
\text { os } \\
\text { francese } \\
\text { s adultos } \\
\text { com } \\
\text { obesida } \\
\text { de. }\end{array}$ & $\begin{array}{l}\text { utilizou a } \\
\text { regressão } \\
\text { logística } \\
\text { multifatorial } \\
\text { para identificar } \\
\text { as } \\
\text { individualidade } \\
\text { s entre os } 340 \\
\text { pacientes } \\
\text { internados por } \\
\text { CoviD-19 em } \\
\text { dois hospitais } \\
\text { da França - } \\
\text { Lyon e Lille - } \\
\text { que seriam } \\
\text { relevantes no } \\
\text { desenvolviment } \\
\text { o da forma } \\
\text { grave patologia. }\end{array}$ & $\begin{array}{l}\text { Dos } 340 \\
\text { pacientes } \\
\text { admitidos no } \\
\text { hospital } \\
\text { Lyon } 230 \\
\text { apresentara } \\
\text { m a forma } \\
\text { leve da } \\
\text { doença } \\
\text { não } \\
\text { precisaram } \\
\text { de } \\
\text { tratamento } \\
\text { intensivo } e \\
\text { 110 } \\
\text { indivíduos } \\
\text { desenvolver } \\
\text { am a forma } \\
\text { grave. Entre } \\
\text { os } \\
\text { indivíduos } \\
\text { que foram } \\
\text { internados } \\
\text { na UTI a } \\
\text { prevalência } \\
\text { da } \\
\text { obesidade } \\
\text { oi entre } 1,33 \text { maior }\end{array}$ \\
\hline
\end{tabular}




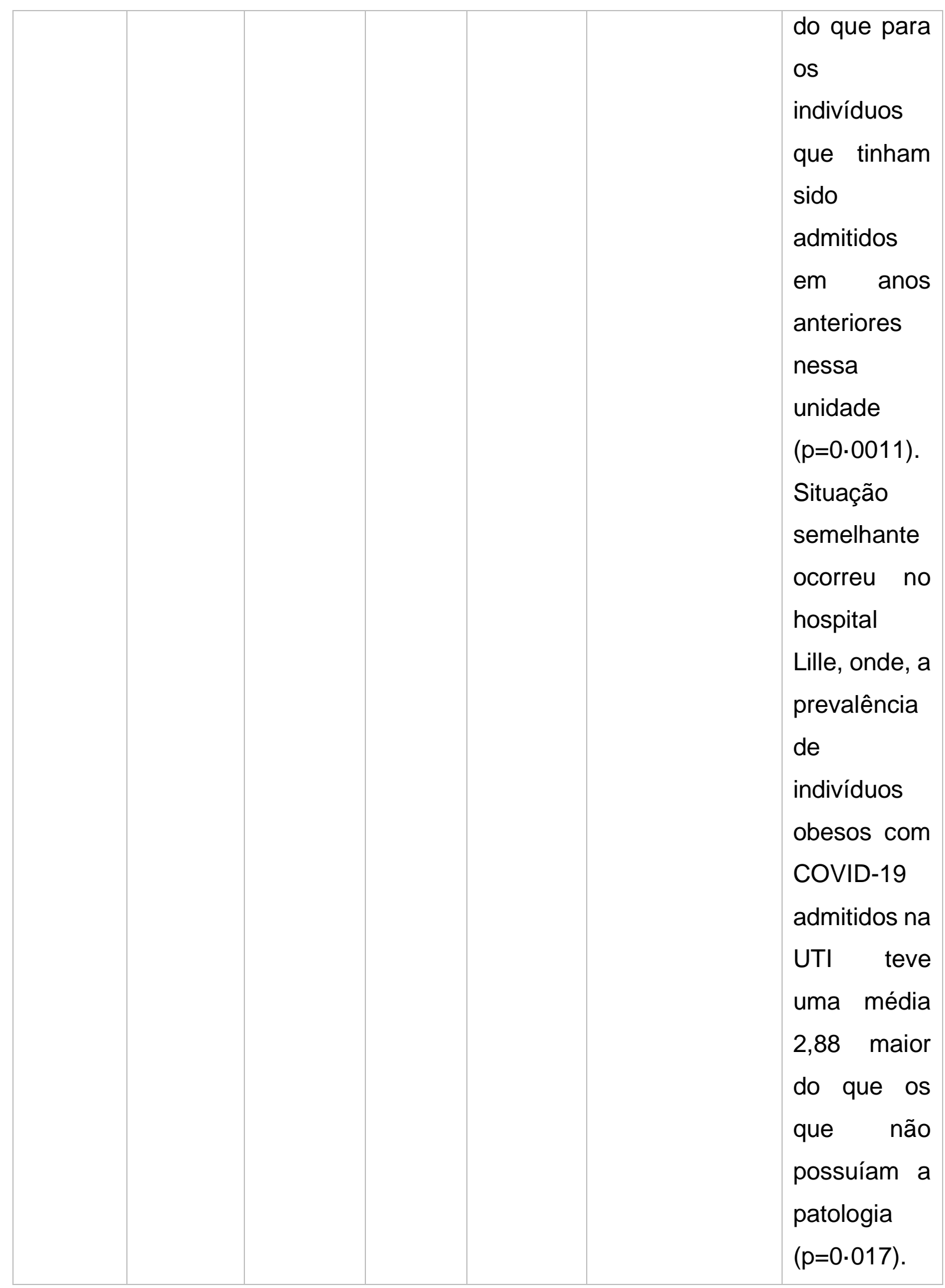




\section{DISCUSSÃO}

Esta revisão integrativa de literatura buscou elucidar e compilar as evidências científicas disponíveis e publicadas nos diversos países, para que seja possível identificar a relação entre a obesidade e a COVID-19, já que ambas possuem uma característica em comum: são doenças que estão em pleno crescimento mundial.

O COVID-19, também chamado de o novo coronavírus, desde dezembro de 2019 resultou em uma considerável morbimortalidade global. Esta nova pandemia trouxe um enorme impacto na saúde humana e no desenvolvimento econômico, excedendo a marca dos nove milhões de casos e mais de 300.000 de mortes em todo o mundo (FENG, 2020). A COVID-19 iniciou-se em um pequeno foco em Wuhan, na China, e em menos de cinco meses, se espalhou para mais de nove milhões de pessoas em quase todos os países do mundo, elevando a preocupação da maioria dos governos e sistemas de saúde pública. Trazendo um enorme impacto na organização mundial por um tempo indeterminado, pois a mesma afetou fortemente as relações sociais, econômicas e políticas (SIRONI, 2020).

A COVID-19 foi classificada como a maior pandemia do século, acometendo a maioria dos países do mundo, e percebeu-se que os portadores de Doenças Crônicas Não Transmissíveis (DCNT), incluindo a Hipertensão Arterial Sistêmica (HAS), Doenças Cardiovasculares (DCV), Diabetes Mellitus (DM), patologias pulmonares e a obesidade são os que evoluem de forma mais grave a doença (DRUCKER, 2020).

A idade avançada e a presença de outras comorbidades, como hipertensão, doenças cardiovasculares, diabetes mellitus e doenças pulmonares tem sido relatado consistentemente como fator para o prognóstico da COVID-19. Entretanto, a associação entre a obesidade e a hospitalização na população mais jovem tem sido mencionada. Aumentou-se a preocupação com a crescente prevalência de obesidade em todo o mundo, devido o impacto em agravar a pandemia (GRASSELLI et al., 2020; YANG et al., 2020). Dessa forma, o aumento da mortalidade ocasionada após a infecção pelo COVID-19 tem sido associado a obesidade, no qual destacou-se a importância da nutrição no prognóstico da COVID-19 (SIRONI, 2020). 
A Organização Mundial da Saúde relata que um importante fator de risco para se tornar gravemente doente com o novo coronavírus é ter doenças crônicas não transmissíveis, como a obesidade. Um estudo do Centro Nacional de Pesquisa e Auditoria de Cuidados Intensivos do Reino Unido menciona que dois terços das pessoas que desenvolveram complicações graves ou fatais relacionadas ao COVID19 apresentaram sobrepeso ou obesidade. Um relatório da Itália mostrou que 99\% das mortes ocorreram em pacientes com doenças pré-existentes não transmissíveis, como a obesidade, a hipertensão, diabetes mellitus tipo 2, doença cardíaca, danos nos rins, e cancro (ALAM; NG; LARBI, 2020; MALAVAZOS et al., 2020).

A associação da fisiologia e imunologia entre a obesidade e a COVID-19 ainda não está totalmente esclarecida, no entanto, correlacionou-se a inflamação crônica gerada pela obesidade como um fator agravante do estado de saúde para pacientes acometidos por diversos patógenos como a SARS-CoV2 e a Influenza A. Entre as alterações sistêmicas promovidas pela obesidade estão a alimentação industrializada, a infiltração de patógenos por meio da hipermeabilidade intestinal derivada de alterações ambientais, a redução do sistema imunológico, a infiltração de macrófagos no tecido adiposo, a liberação de espécies reativas de oxigênio (EROS), a secreção de diversas citocinas pró-inflamatórias, Interleucina $1 \beta$ (IL1 $\beta$ ), interleucina 6 (IL6) e o Fator de Necrose Tumoral (FNT) (TAMARA; TAHAPARY, 2020).

Ademais, a exaustão do sistema imunológico no indivíduo obeso é relacionada a dificuldade de atingir o balanço imunológico. Por terem que lidar concomitantemente com a inflamação associada pela obesidade e com a multiplicação rápida da carga viral da COVID-19, ocasionam aumento desproporcional das células T, o que culmina em uma grande secreção de proteínas inflamatórias, seguido de infiltração pulmonar por parte desses fatores e estas respostas estão associadas a exaustão do sistema imunológico nos pacientes acometidos pela infecção.

Através das evidências, constatou-se que a obesidade exerce um risco independente para resultados adversos a COVID-19 (MALAVAZOS, et al, 2020), no qual inicialmente associavam somente a condição geriátrica, as alterações do sistema imunológico e o aumento da suscetibilidade às infecções. Assim sendo, a obesidade 
é um fator de risco para uma má progressão da doença por COVID-19, principalmente em indivíduos não idosos (HEREDIA; GÓMEZ-MARTíNEZ; MARCOS, 2012; TAMARA; TAHAPARY, 2020).

Pessoas com obesidade em todo o mundo já estão em alto risco de complicações graves do COVID-19, em virtude do aumento do risco de doenças crônicas que a obesidade gera. A obesidade é um fator de risco para a gravidade da SARS-CoV2, exigindo maior atenção às medidas preventivas em indivíduos suscetíveis (RYAN; RAVUSSIN; HEYMSFIELD, 2020; SIMONNET et al., 2020).

Por fim, apesar de os trabalhos científicos estarem sendo produzidos e publicados em todo o mundo, diversas questões que envolvem as DCNTs, em especial a obesidade, e a COVID-19 ainda precisam ser elucidados à luz de evidências que possam contribuir para o manejo associado das duas patologias.

\section{LIMITAÇÕES}

Por ser uma doença nova e que está atualmente em propagação, poucos estudos foram publicados até o momento correlacionando e explicando a relação entre a obesidade e a COVID-19. Com isso, são necessários que estudos de intervenção sejam realizados para que se constate a interação metabólica que existe entre esses fatores, assim como, os possíveis tratamentos que podem ser utilizados para melhorar o manejo terapêutico no paciente com obesidade e o novo coronavírus.

\section{CONSIDERAÇÕES FINAIS}

Diferindo das outras pandemias que acometeram a população mundial nos séculos passados, a pandemia da COVID-19 possui a particularidade de ser altamente contagiosa, o que permite o seu alastramento pelo mundo de maneira sem precedentes e ocasionando muitas mortes. Algumas alterações metabólicas resultam em complicações dos agravos ocasionados pela doença e entre elas estão as DCNT, com destaque para a obesidade. Essas comorbidades são fatores importantes para o prognóstico destes pacientes, trazendo assim, maiores cuidados com os indivíduos 
que possuem fatores de risco. A literatura científica tem tentado dar maior atenção aos pacientes com obesidade diante desta pandemia, no entanto, são necessários mais estudos, tanto da Covid-19, quanto da sua relação com a obesidade.

\section{REFERÊNCIAS}

ALAM, Iftikhar; NG, Tze Pin; LARBI, Anis. Does inflammation determine whether obesity is metabolically healthy or unhealthy? The aging perspective. Mediators Inflamm. Out. 2012. Disponível em: https://pubmed.ncbi.nlm.nih.gov/23091306/. Acesso em: 04/04/2020.

CAUSSY, Cyrielle et al. Prevalence of obesity among adult inpatients with COVID-19 in France. Lancet Diabetes Endocrinol. v.8 n.7 p. 562-564. Maio, 2020. Disponível em: https://www.ncbi.nlm.nih.gov/pmc/articles/PMC7234780/. Acesso em: 23/05/2020.

DIETZ, William, SANTOS-BURGOA, Carlos. Obesity and its Implications for COVID19 Mortality. Obesity (Silver Spring). v.28, n.6, p. 35-44. Jun. 2020. Disponível em: https://pubmed.ncbi.nlm.nih.gov/32237206/. Acesso em: 23/06/2020.

DRUCKER, Daniel. Coronavirus Infections and Type 2 Diabetes-Shared Pathways with Therapeutic Implications. Endocr Rev. v. 41, n.3, p.1-11, Jun. 2020. Disponível em: https://pubmed.ncbi.nlm.nih.gov/32294179/. Acesso em: 13/05/2020.

FENG, Wei. et al., Severe acute respiratory syndrome coronavirus 2 (SARS-CoV-2): a review. Mol Cancer. v.19, n.1, p.100-110. Jun. 2020. Disponível em: https://www.ncbi.nlm.nih.gov/pmc/articles/PMC7264920/. Acesso em: 14/06/2020.

GAO, Feng., et al. Obesity is a risk factor for greater COVID-19 severity. Diabetes Care. Maio, $2020 . \quad$ Disponível em: https://care.diabetesjournals.org/content/early/2020/05/12/dc20-0682. Acesso em: 17/06/2020. 
GRASSELLI, Giacomo. et al., Baseline Characteristics and Outcomes of 1591 Patients Infected With SARS-CoV-2 Admitted to ICUs of the Lombardy Region, Italy. JAMA. v.323, n.16, p. 1574-1581. Abr. 2020. Disponível em: https://pubmed.ncbi.nlm.nih.gov/32250385/. Acesso em: 27/04/2020.

HEREDIA, Fátima Pérez, GÓMEZ-MARTÍNEZ, Sonia, MARCOS, Ascensión. Obesity, inflammation and the immune system. Proc Nutr Soc. v.71, n.2, p.332-338. Maio, 2012. Disponível em: https://pubmed.ncbi.nlm.nih.gov/22429824/. Acesso em: $13 / 06 / 2020$.

HONCE, Rebekah, SCHULTZ-CHERRY, Stacey. Impact of obesity on influenza A virus pathogenesis, immune response, and evolution. Front Immunol. v.10, n.10. p.71-81. Maio 2019. Disponível em: https://www.ncbi.nlm.nih.gov/pmc/articles/PMC6523028/. Acesso em: 04/04/2020.

HUANG, Jiao-Feng et al. Letter to the Editor: Obesity hypoventilation syndrome and severe COVID-19. Metabolism. v.108, n.15. Jul. 2020. Disponível em: https://www.ncbi.nlm.nih.gov/pmc/articles/PMC7195293/. Acesso em: 25/07/2020.

IZQUIERDO, Andrea et al. Leptin, Obesity, and Leptin Resistance: Where Are We 25 Years Later?. Nutr. v.11, n.11, p.270-271 Nov. 2019. Disponível em: https://www.ncbi.nlm.nih.gov/pmc/articles/PMC6893721/. Acesso em: 04/04/2020.

KAMPF et al. Persistence of coronaviruses on inanimate surfaces and its inactivation with biocidal agents. J Hosp Infect. v.104, n.3, p.246-251. Mar. 2020. Disponível em: https://www.journalofhospitalinfection.com/article/S0195-6701(20)30046-3/fulltext. Acesso em: 03/04/2020.

LAI, Chih-Cheng et al. Severe acute respiratory syndrome coronavirus 2 (SARS-CoV2) and coronavirus disease-2019 (COVID-19): The epidemic and the challenges. Int $\mathbf{J}$ Antimicrob Agents. v.55, n.3, p.105-114. Fev. 2020. Disponível em: https://pubmed.ncbi.nlm.nih.gov/32081636/. Acesso em: 05/04/2020. 
LI, Qun. et al. Early transmission dynamics in Wuhan, China, of novel coronavirusinfected pneumonia. N Engl J Med. v.382, n.13, p.1199-1207. Mar. 2020. Disponível em: https://pubmed.ncbi.nlm.nih.gov/31995857/. Acesso em: 03/05/2020.

MALAVAZOS, Alexis Elias. et al. Targeting the Adipose Tissue in COVID-19. Obes Soc. v.28, n.7, p.1178-1179, Jul. $2020 . \quad$ Disponível: https://onlinelibrary.wiley.com/doi/full/10.1002/oby.22844. Acesso em: 03/07/2020.

RYAN, Paul MacDaragh, CAPLICE, Noel. Is Adipose Tissue a Reservoir for Viral Spread, Immune Activation and Cytokine Amplification in COVID-19. Obesity (Silver Spring). v.28. n.07, p. 1191-1194. Jul. 2020. Disponível em: https://onlinelibrary.wiley.com/doi/full/10.1002/oby.22843. Acesso em: 30/07/2020.

RYAN, Donna, RAVUSSIN, Eric; HEYMSFIELD, Steven. COVID 19 and the Patient with Obesity - The Editors Speak Out. Obes Soc. v.28, n.5, p.847-847, Maio 2020. Disponível em: https://pubmed.ncbi.nlm.nih.gov/32237212/. Acesso em: 18/05/2020.

SIFUENTES-RODRíGUEZ, Erika, PALACIOS-REYES, Deborah. COVID-19: The outbreak caused by a new coronavirus. COVID-19: la epidemia causada por un nuevo coronavirus. Bol Med Hosp Infant Mex. v.77, n.2, p.47-53, Abr. 2020. Disponível em: http://www.scielo.org.mx/scielo.php?script=sci_arttext\&pid=S166511462020000200047. Acesso em: 28/04/2020.

SIMONNET, Arthur, et al. High Prevalence of Obesity in Severe Acute Respiratory Syndrome Coronavirus-2 (SARS-CoV-2) Requiring Invasive Mechanical Ventilation [published online ahead of print, 2020 Apr 9]. Obesity (Silver Spring). v.28, n.7, p. 1195-1199 Jul. 2020.2 Disponível em: https://onlinelibrary.wiley.com/doi/full/10.1002/oby.22831. Acesso em: 13/07/2020.

SIRONI, Manuela. et al. SARS-CoV-2 and COVID-19: A genetic, epidemiological, and evolutionary perspective. Infectar Genet. Evol. v.84. Maio. 2020. Disponível em: https://pubmed.ncbi.nlm.nih.gov/32473976/. Acesso em: 30/05/2020. 
SOUZA, Marcela Tavares, SILVA, Michelly Dias, CARVALHO, Rachel. Revisão integrativa: o que é e como fazer. Einstein. v.8, n.1, p.102-106. Mar. 2010. Disponível em:

https://www.scielo.br/scielo.php?pid=S167945082010000100102\&script=sci_arttext\&tlng=pt. Acesso em: 03/04/2020.

TAMARA, Alice, TAHAPARY, Dicky. Obesity as a predictor for a poor prognosis of COVID-19: A systematic review. Diabetes Metab Syndr. v.14, n.4, p.655-659. Jul. 2020. Disponível em: https://www.ncbi.nlm.nih.gov/pmc/articles/PMC7217103/. Acesso em: 27/07/2020.

WANG, Chen et al. A novel coronavirus outbreak of global health concern. Lancet. v.395, n.23, p.470-473. Fev. 2020. Disponível em: https://pubmed.ncbi.nlm.nih.gov/31986257/. Acesso em: 13/05/2020.

WU et al. Early antiviral treatment contributes to alleviate the severity and improve the prognosis of patients with novel coronavirus disease (COVID-19). J Intern Med. v.288, n.1, p.128-138. Jul. $2020 . \quad$ Disponível em: https://onlinelibrary.wiley.com/doi/full/10.1111/joim.13063. Acesso em: 30/07/2020.

YANG, Xiaobo. et al. Clinical course and outcomes of critically ill patients with SARSCoV-2 pneumonia in Wuhan, China: a single-centered, retrospective, observational study. Lancet Respir Med. v.8, n.5, p.475-481. Fev. 2020. Disponível em: https://pubmed.ncbi.nIm.nih.gov/32105632/. Acesso em: 03/04/2020.

ZHAO, Shi et al. Preliminary estimation of the basic reproduction number of novel coronavirus (2019-nCoV) in China, from 2019 to 2020: a data-driven analysis in the early phase of the outbreak. Int $\mathbf{J}$ Infect Dis. v.92, n.3, p.214-217, Mar. 2020. Disponível em: https://pubmed.ncbi.nlm.nih.gov/32007643/. Acesso em: 01/04/2020.

ZHENG, Kenneth et al. Letter to the Editor: Obesity as a risk factor for greater severity of COVID-19 in patients with metabolic associated fatty liver disease. Metabolism. v.108, n.15, p.42-44. Abr. 2020. Disponível em: https://www.ncbi.nlm.nih.gov/pmc/articles/PMC7166301/. Acesso em: 23/04/2020. 
Enviado: Outubro, 2020.

Aprovado: Novembro, 2020. 